\title{
Evaluation of fire damage to the steel structure of an industrial shed
}

\author{
Marta Lutomirska ${ }^{1, *}$, and Szczepan Lutomirski ${ }^{1}$ \\ ${ }^{1}$ Warsaw University of Technology, The Faculty of Civil Engineering, Poland
}

\begin{abstract}
The study concerns an analysis of fire damage to the steel structure of an industrial shed. The shed was used as storage for woodchips, which are an easily inflammable material. Despite the fact that the fire did not affect the entire structure, it resulted in an excessive deformation of the roof elements, damage to curtain walls, and the conveyer. The state of safety of the remaining structure was evaluated based on the performed investigation, study of the archive documentation and static calculations. The critical temperature for steel structural elements was estimated. The structure elements requiring replacement were identified.
\end{abstract}

\section{Introduction}

The scope of the paper is to present an analysis of damage to a steel structure of an industrial shed due to fire. The shed was used as storage for woodchips - small pieces of wood, being residues from the forest and sawmill industries. The woodchips were processed and used in the production of fiberboards. The fire did not spread out and did not affect the entire structure. It resulted in local damages such as an excessive deformation of the roof structure, and damage to curtain walls and the conveyer belt. In Fig.1, the view of the west elevation after partial disassembling of the roof and curtain walls is shown.

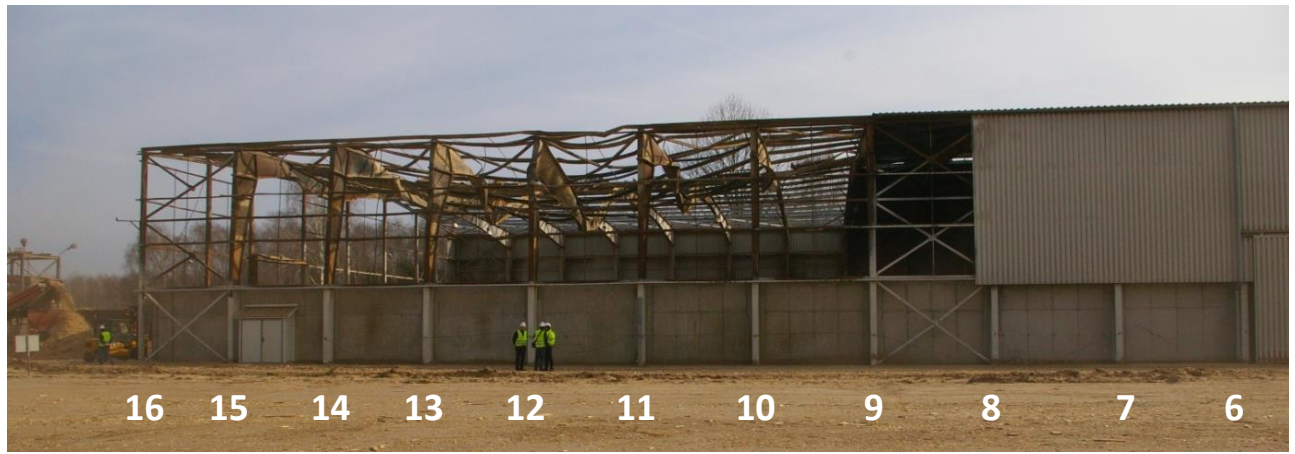

Fig. 1. West elevation of the damaged industrial shed in the axis C.

\footnotetext{
*Correspondin author: m.lutomirska@il.pw.edu.pl
} 
It was estimated that some of the structural elements were subjected to a peak temperature of $700^{\circ} \mathrm{C}$ for several dozens of minutes. Based on our own investigation, archive documentation [1], and static calculations, the state of safety of the remaining structure was evaluated.

\section{Description of the industrial shed's structure}

The steel industrial shed was committed to exploitation in 2009. Its axial dimensions were the following: length $108 \mathrm{~m}$, width $72 \mathrm{~m}$, and height $12 \mathrm{~m}$. The schema of the steel structure of the industrial shed is presented in Fig. 2 and Fig. 3 [1]. The machines for cutting or chipping of wood were localized outside the shed, on the north side. The movable floor was located on the opposite side of the shed. The central part of the structure was occupied by a conveyor belt for transportation of woodchips, which was fixed to the roof structure. The woodchips were stored along the retaining walls. The gable roof had an incline of $10 \%$.

The main structural elements were steel frames spaced every $4.80 \mathrm{~m}$. The steel profiles were manufactured of S355 JR steel. Sizing of the frame corresponds to the distribution of the bending moments, which results in variable cross sections: height and thickness of webs as well as width and thickness of flanges.

The steel columns were located beyond the reinforced concrete retaining walls and had pin connections to the foundation. The frames' cross-sections of the I-shaped profiles were variable: the height was varying between 508 and $1329 \mathrm{~mm}$, the flanges were $250 \mathrm{~mm}$ wide and 12,16 , and $20 \mathrm{~mm}$ thick, the web thickness was 10 and $12 \mathrm{~mm}$. The side rails were fixed to the columns. The total height of the side rails varied between 724 and $1374 \mathrm{~mm}$. The width of the side rails' flanges was equal to 250 and $300 \mathrm{~mm}$. Their thickness was 10 , $12,16,20$ and $25 \mathrm{~mm}$, while the web's thickness was 8,10 and $12 \mathrm{~mm}$. In the mid span of the side rails, stiffeners of steel pipes $\varnothing 33.7 / 2.6$ were designed. For the corner columns, the columns along the gable walls, and the eave beams steel profiles HEB 200 of S355 JR steel were used. The purlins on the roof were performed of steel profiles ZW200x2. In the mid span of the purlins stiffeners of steel bar $Ø 12$ were applied.

The connections were performed with the use of high strength bolts class 10.9. The connections between the eave beams, and the connections between the eave beams and the columns were fixed, which resulted in a high bending moment in the frame corner. This justified the increased cross sections at that place.

To provide lateral stiffening of the structure the lateral stiffeners of square pipes $100 \times 4$ were used. There were three levels of the stiffeners along the longer side of the shed and one level of the stiffeners along the gable wall. The longitudinal and transversal stiffeners were provided also at the roof level, which allowed for treating the roof as a plate element. Therefore, the entire structure could be analyzed as a three-dimensional system. The system of frames, purlins, side rings and bracings was strengthened additionally in the opposite direction with braces of angle bars $60 \times 5 \mathrm{~mm}$.

The cladding of the structure consisted of reinforced concrete retaining wall, corrugated metal sheets, five entrance gates, and fifteen skylights of polycarbonate panels for natural lighting. Up to $3.5 \mathrm{~m}$ in height, there were reinforced concrete retaining walls of concrete C20/25 and reinforcing steel 34GS (A-III) i St3S (A-I). They were $30 \mathrm{~cm}$ thick and they were monolithically connected with the reinforced concrete foundation slab. The corrugated metal sheets T35/207 of thickness $0.6 \mathrm{~mm}$ were applied to the walls' cladding. They were fixed to the side rails with $\mathrm{C} 160 \times 60 \times 5$ profiles. For the roof $0.75 \mathrm{~mm}$ thick corrugated metal sheets TR65/207 were used. The cladding was supposed to transfer the load due to the snow and wind to the steel structure of the shed. It required a dense net of the support points transferring the load to the steel structure. 


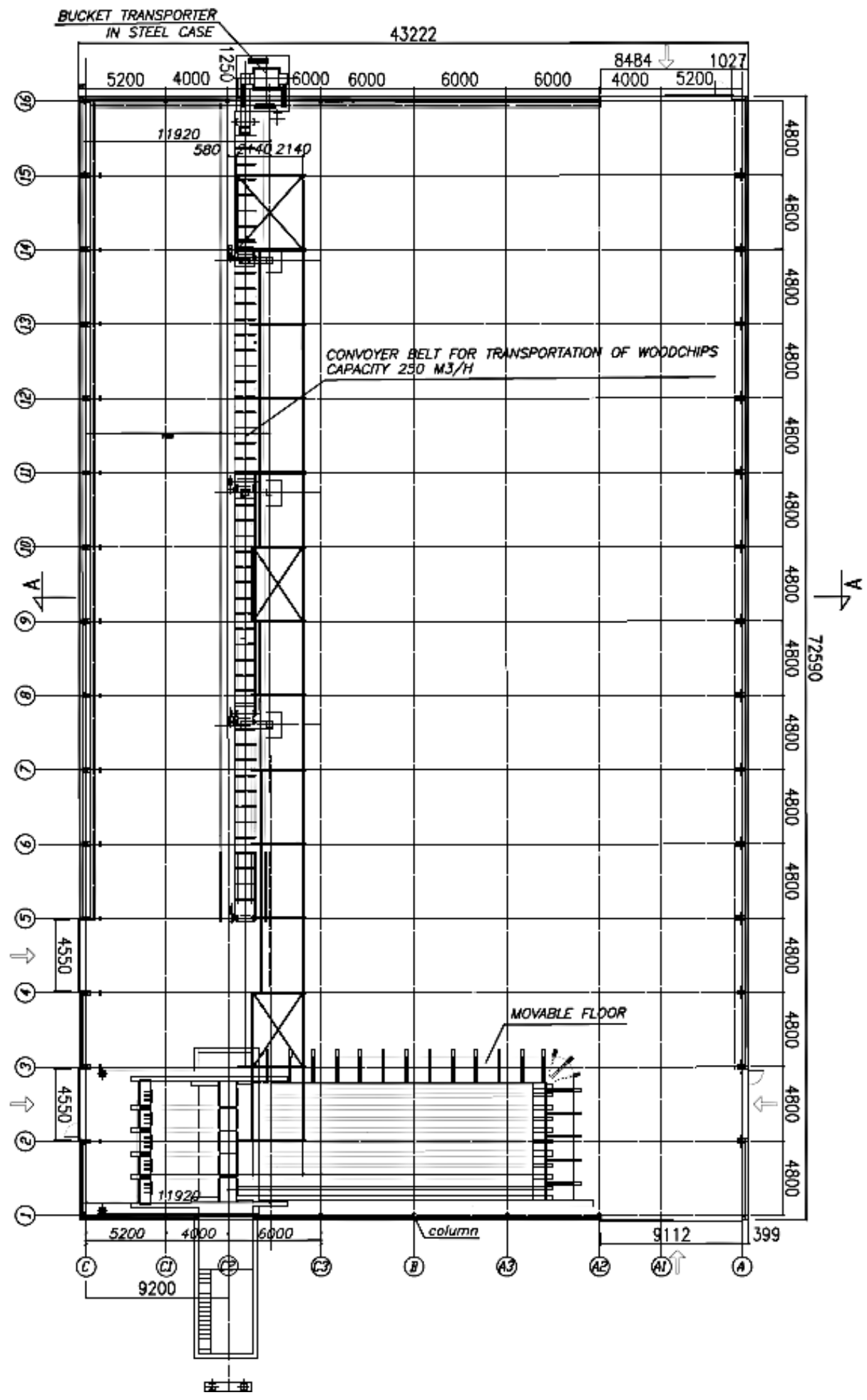

Fig. 2. Schema of the industrial shed's structure. 


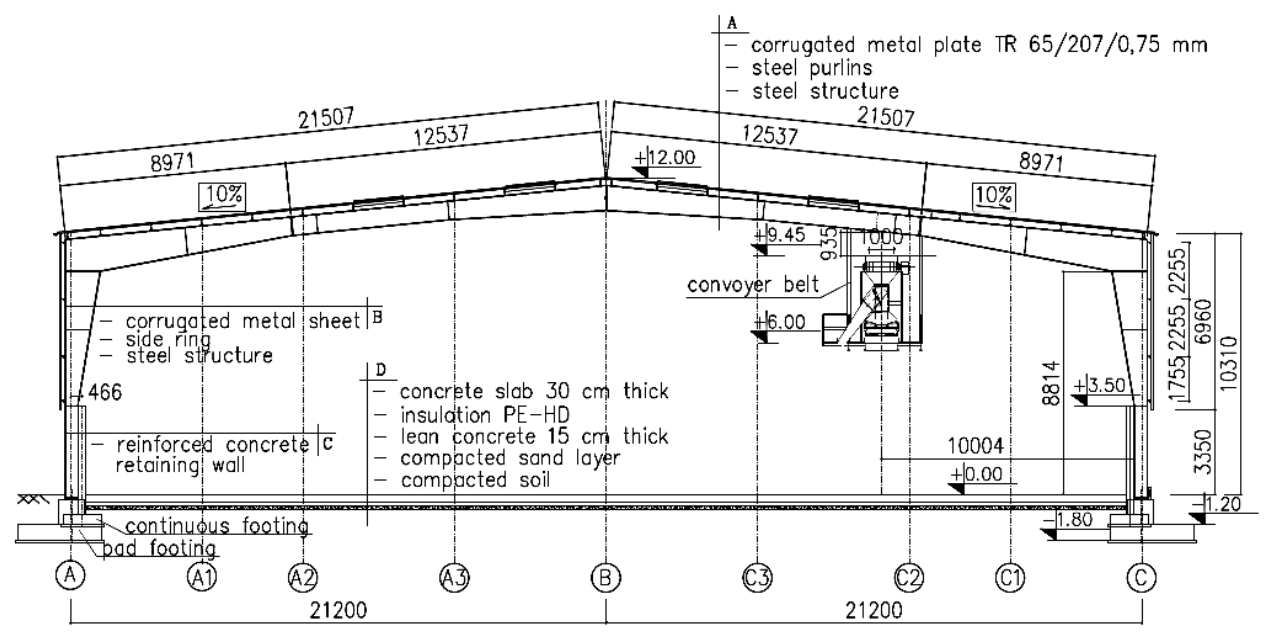

Fig. 3. Cross section A-A.

\section{Evaluation of fire damage}

Fire generates a variety of risks to the structural elements. High temperature leads to changes of the mechanical properties of the materials, and their strength [2]. Their magnitude depends on dynamics of the fire: its duration, the way the fire was extinguished, the elements' thickness, etc. The dynamics of fire are influenced by the geometry of the structure, access to air, the type and quantity of inflammable materials and thermal characteristics of the external walls [3].

Due to a high number of factors the duration and the temperature of fire is not easy to evaluate. During the fire, the woodchips were stored in the shed. For humidity between 20 $60 \%$ the heating value for woodchips is $6-20 \mathrm{MJ} / \mathrm{kg}$, while the weight of 1 cubic meter may vary between 220 and $430 \mathrm{~kg}$. Therefore, the fire load density was estimated at $500 \mathrm{MJ} / \mathrm{m} 2$ [4], and the fire resistance class E was assumed. According to the law regulations [4], the design of the shed did not have to include fire safety.

The fire started from woodchips on the conveyor belt. The distance between the source of the fire and the roof was smaller than $1 \mathrm{~m}$. The woodchips, the conveyor belt and the electrical installations were easily inflammable materials. The source of fire was identified quickly. However, extinguishing of the burning heaps of woodchips took more time. Application of water on the heated steel elements led to thermal shock and damages. The most extensive fire damage was identified between axes B - C and 9 - 16 (Fig. 2 and Fig. 4). Damage to the adjacent structure between axes A - B and $9-16$ is significantly smaller (Fig. 5).

There are several curves describing change of the temperature in time [5]. The commonly used curve according to PN-EN 1991-1-2:2006 [6] was assumed.

$$
\theta_{\mathrm{g}}=20+345 \log (8 \mathrm{t}+1)
$$

where:

$\theta_{\mathrm{g}}-$ gas temperature $\left[{ }^{0} \mathrm{C}\right]$,

$\mathrm{t}$ - time [min]. 


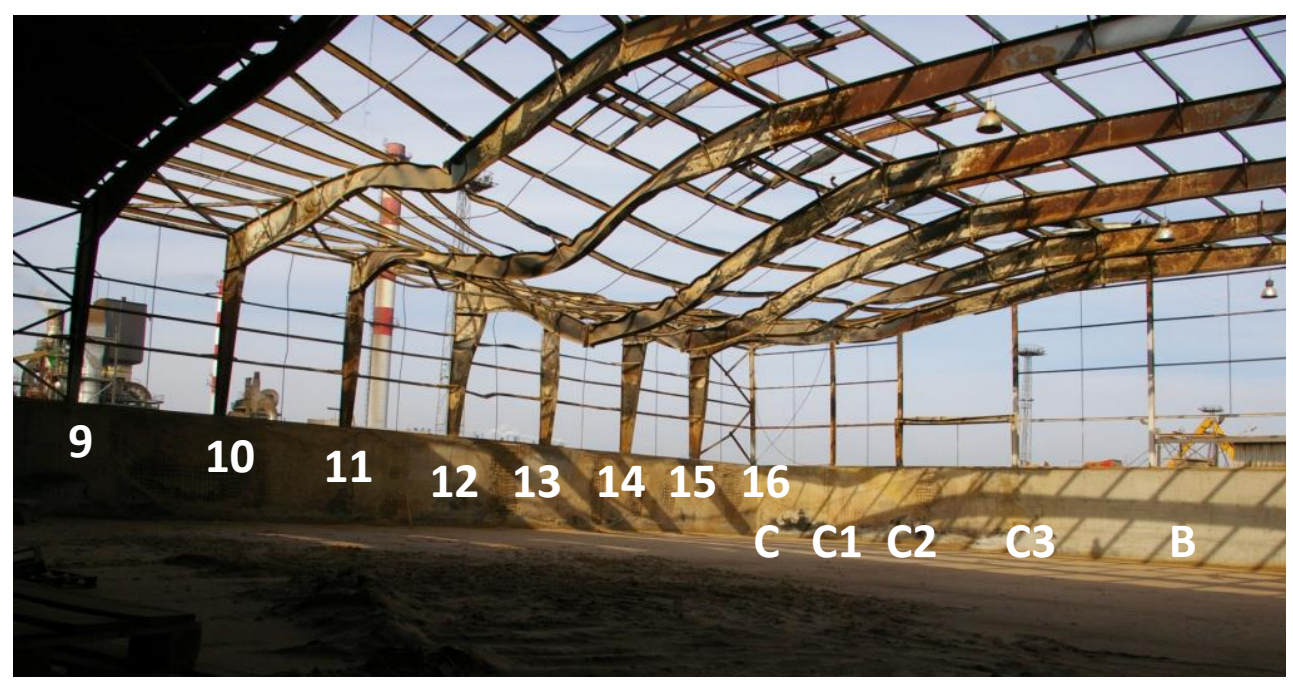

Fig. 4. Deformation of the steel structure between axis B - C and 9-16.

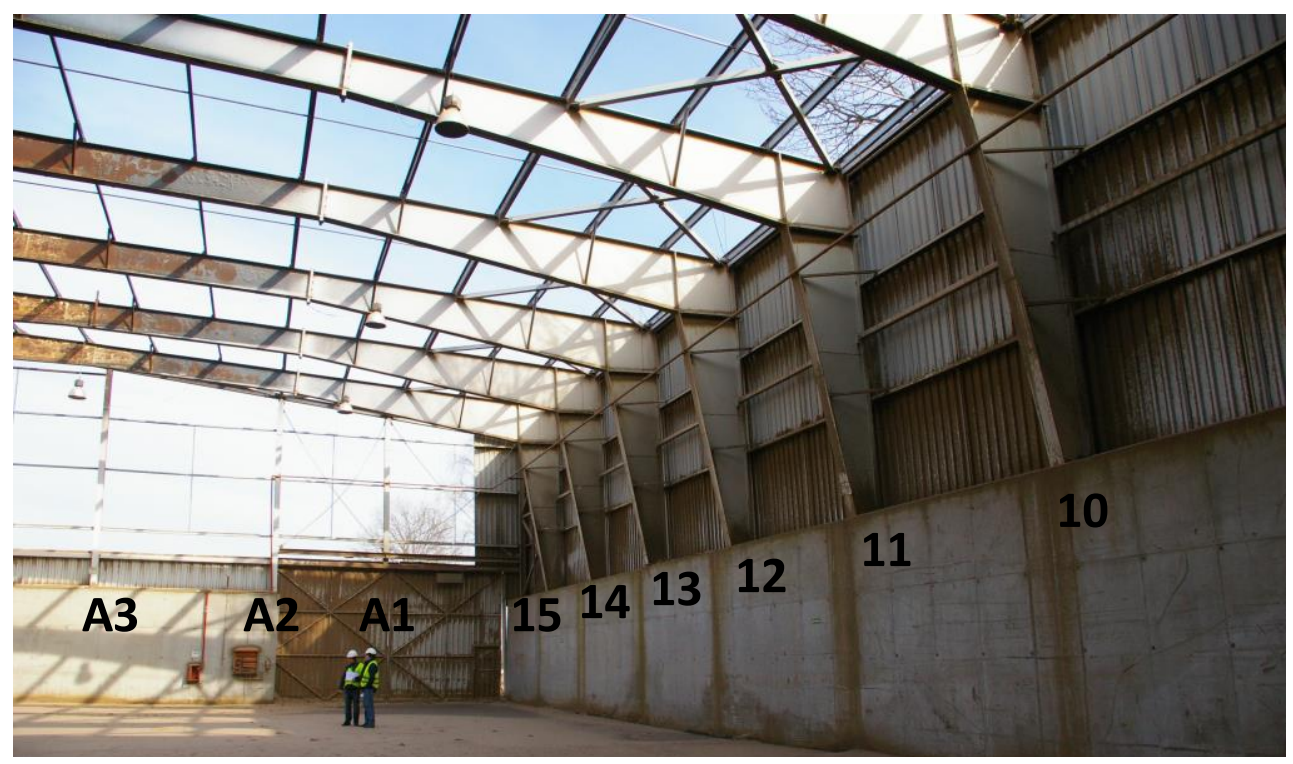

Fig. 5. Shed's structure between the axis A - B and $10-16$.

According to the Equation (1) the temperature increases constantly and after $15 \mathrm{~min}$ reaches $738.5^{\circ} \mathrm{C}$. The equation assumes some simplifications. It assumes constant temperature in the building interior. The equation does not include fire load density, thermal characteristics of walls, and geometry of the structure.

Steel is characterized with high thermal conductivity $\lambda_{\mathrm{a}}$. At $0^{0} \mathrm{C}$ it equals to $54 \mathrm{~W} /(\mathrm{mK})$ and decreases to $27.3 \mathrm{~W} /(\mathrm{mK})$ at $800^{\circ} \mathrm{C}$. For simplified calculations the thermal conductivity for temperature ranges $20^{\circ} \mathrm{C} \leq \theta_{\mathrm{a}}<800^{\circ} \mathrm{C}$, may be calculated using the equation:

$$
\lambda_{\mathrm{a}}=54-3,33 \times 10^{-2} \theta_{\mathrm{a}}[\mathrm{W} /(\mathrm{mK})]
$$


Despite very high thermal conductivity, after cleaning of the structure, no blisters, no blackening nor changes in the paint colour in the vicinity of the vertical convection column were observed (the region A2-A and 9-16). It means that the temperatures were lower than the critical temperature of the structural steel coating (which is about $420^{\circ} \mathrm{C}$ ) and the fire lasted a relatively short time. Also the bottom parts of the columns did not deform (Fig. 6). Based on the observation of damage to the styrofoam between columns and the retaining wall, it was estimated that the temperature in this region slightly exceeded $100^{\circ} \mathrm{C}$. Styrofoam starts to shrink at temperatures above $100^{\circ} \mathrm{C}$, then it melts. It burns at temperatures over $350^{\circ} \mathrm{C}$. The frames without fire protection coatings (Fig. 4 and 5) lost their load bearing capacity.

Critical temperature $\theta_{\mathrm{a}, \mathrm{cr}}$ can be calculated according to PN-EN 1993-1-2 [7]:

$$
\theta_{\mathrm{a}, \mathrm{cr}}=39.19\left[\frac{1}{0.9674 \mu_{0}^{3.833}}-1\right]+482
$$

Load bearing capacity utilization for the frame $\mu_{0 \mathrm{w}}$ was evaluated at the level of $0.2-0.3$. Therefore the critical temperature could be close to $700^{\circ} \mathrm{C}$. The most damaged elements were those located close to the source of fire and exposed to fire from three sides (Fig. 4 and 5).

Steel structures subjected to fire reach high temperatures quickly in entire cross sections, which results in a drop in their mechanical properties. In the Eurocode 3 Part 2-1 [7], the stress-strain relationship $\sigma-\varepsilon$ was assumed for temperature $20^{\circ} \mathrm{C}$ and reduction factors $\mathrm{k}_{\mathrm{i}, \theta}$ for carbon steel at elevated temperatures were used (Fig. 7). It is observed that the yield strength remains unaffected up to $400^{\circ} \mathrm{C}$, while proportional limit and slope of linear elastic range are affected by temperatures starting from $100^{\circ} \mathrm{C}$. Increase of those two values results in decrease of stiffness followed by high deformations and loss of load bearing capacity.

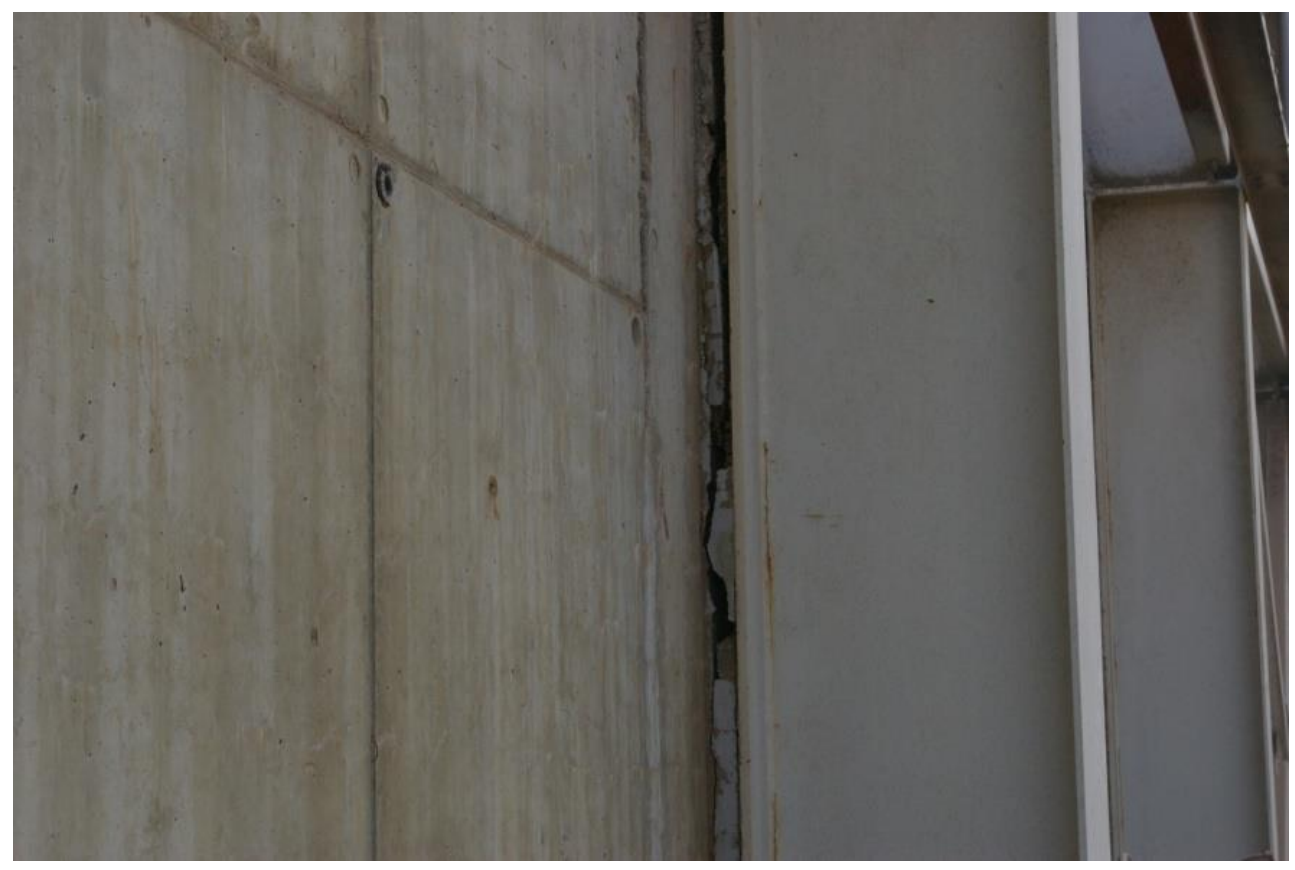

Fig. 6. Bottom part of the column in the axis C-14 . 


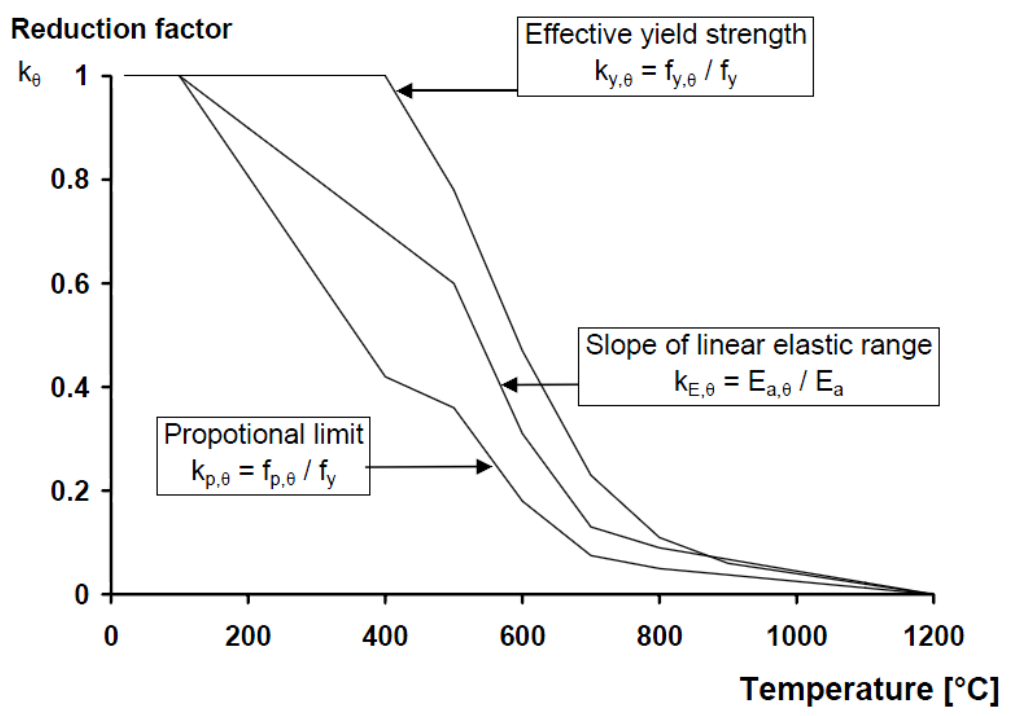

Fig. 7. Reduction factors for stress-strain relationship of carbon steel at elevated temperatures [Eurocode 3. Part 3-2 Figure 3.2]

\section{Control calculations}

Control static calculations to check the safety of the steel structure were performed according to the Eurocodes. The Ultimate Limit State Strength was checked. The environmental actions were limited to snow load on the roof. For the calculations a schema of one span two pin frame was assumed. The variable cross sections of were designed as stepped ones.

Using a computer program, the internal forces were derived. For the frame corner, the longitudinal force was $166.23 \mathrm{kN}$ and the bending moment was $393.08 \mathrm{kNm}$. Therefore:

For the fibres in tension:

$$
\frac{N_{E d}}{N_{R k}}+\frac{M_{x, E d}}{M_{X, R K}}=\frac{-166.23}{275 \times 35.5}+\frac{139308}{9659.9 \times 35.5}=0.389<1
$$

For the fibres in compression:

$$
\frac{\mathrm{N}_{\mathrm{Ed}}}{\mathrm{N}_{\mathrm{Rk}}}+\frac{\mathrm{M}_{\mathrm{x}, \mathrm{Ed}}}{\mathrm{M}_{\mathrm{X}, \mathrm{RK}}}=\frac{-166.23}{275 \times 35.5}-\frac{139308}{12314 \times 35.5}=|-0.336|<1
$$

For the column, the longitudinal force was $216.70 \mathrm{kN}$ and the bending moment was $1393.08 \mathrm{kNm}$. Therefore:

For the fibres in tension:

$$
\frac{\mathrm{N}_{\mathrm{Ed}}}{\mathrm{N}_{\mathrm{Rk}}}+\frac{\mathrm{M}_{\mathrm{x}, \mathrm{Ed}}}{\mathrm{M}_{\mathrm{X}, \mathrm{RK}}}=\frac{-216.70}{245 \times 35.5}+\frac{139308}{8713.6 \times 35.5}=0.425<1
$$

For the fibres in compression:

$$
\frac{N_{E d}}{N_{R k}}+\frac{M_{X, E d}}{M_{X, R K}}=\frac{-216.7}{245 \times 35.5}-\frac{139308}{9409 \times 35.5}=|-0.442|<1
$$
0.66 .

Based on the performed calculations the load bearing capacity utilization factor was 


\section{Summary and conclusions}

Steel elements subjected to fire lose their mechanical properties quickly, which results in excessive deformations and loss of load bearing capacity. The critical temperature for the structure was estimated at $700^{\circ} \mathrm{C}$. A higher temperature was achieved only in the direct vicinity of the convection column. The longitudinal axis of the convection column corresponds to the axis of the conveyer belt. The worst damage was observed between axes $\mathrm{B}-\mathrm{C}$ and 9-16. In the distance of a few meters from the convection column, the temperatures were below critical for the structural steel coating (about $420^{\circ} \mathrm{C}$ ) and the damages were not significant.

It was evaluated that the central part of the roof structure between axes 6 and 16 (strip width about $20 \mathrm{~m}$ ) is permanently damaged and requires replacement. Also part of the cladding and ring beams should be replaced (along the axis $\mathrm{C}$ between axes 8 and 16 and along the axis 16 between axes $\mathrm{C}$ and $\mathrm{A} 3$ ). The columns in axis $\mathrm{A}$ and one of four segments of the ring beams are not damaged. As far as regarding columns in the axis $\mathrm{C}$, only their bottom part (up to $3.7 \mathrm{~m}$ ) was not damaged. Therefore, it would possible to cut the profile and replace only the top part of the column. However, that is the cross section of the highest load bearing capacity utilization factor and it may seem more reasonable and convenient to replace the entire column.

All the columns along the axis 16 between the axes $\mathrm{C}$ and $\mathrm{A} 3$ should be disassembled and replaced. The frames in axes 6-8 are not significantly deformed. They could be straightened up by local heating, if it was economically justified. They could be also left for further exploitation without repair, since the deformations would not significantly influence their load bearing capacity.

\section{References}

1. D. Florczak, Structural design of a steel industrial shed, (2008)

2. A. Biegus, IiB, 3, 133-137, (2008)

3. M. Maślak, Trwatość pożarowa stalowych konstrukcji prętowych, (2008)

4. Regualtion by Ministrer Gospodarki Przestrzennej i Budownictwa DzU Nr 75, (2002)

5. M. Abramowicz, R. Kowalski, P. Wróbel, P., TfoCI, 17, 343-350, (2009)

6. Eurocod 1. Part 1-2.

7. Eurodode 3. Part 1-2. 